\title{
Article \\ 2-O-Methylhonokiol Suppresses HCV Replication via TRAF6-Mediated NF-kB Activation
}

\author{
Suyun Jeong ${ }^{1} \mathbb{D}$, Young-seok Lee ${ }^{1} \mathbb{D}$, Kiyoon Kim ${ }^{2}$, Ji-su Yoon ${ }^{1}$, Sungsoo Kim ${ }^{1,2}$, Joohun Ha ${ }^{1,2}$, Insug Kang ${ }^{1,2} \mathbb{D}$ \\ and Wonchae Choe $1,2, *$ (D)
}

1 Department of Biomedical Science, Graduate School, Kyung Hee University, Seoul 02447, Korea; suyanjjang@naver.com (S.J.); wetoo123@gmail.com (Y.-s.L.); jichuu94@khu.ac.kr (J.-s.Y.); sgskim@khu.ac.kr (S.K.); hajh@khu.ac.kr (J.H.); iskang@khu.ac.kr (I.K.)

2 Department of Biochemistry and Molecular Biology, School of Medicine, Kyung Hee University, Seoul 02447, Korea; soowonsky@gmail.com

* Correspondence: wchoe@khu.ac.kr; Tel.: +82-2-961-0940

Citation: Jeong, S.; Lee, Y.-s.; Kim, K.; Yoon, J.-s.; Kim, S.; Ha, J.; Kang, I.; Choe, W. 2-O-Methylhonokiol Suppresses HCV Replication via TRAF6-Mediated NF-kB Activation. Int. J. Mol. Sci. 2021, 22, 6499. https://doi.org/10.3390/ijms22126499

Academic Editors: Hye Gwang Jeong, Hwi-Yeol Yun and Hangun Kim

Received: 24 May 2021

Accepted: 15 June 2021

Published: 17 June 2021

Publisher's Note: MDPI stays neutral with regard to jurisdictional claims in published maps and institutional affiliations.

Copyright: (c) 2021 by the authors. Licensee MDPI, Basel, Switzerland. This article is an open access article distributed under the terms and conditions of the Creative Commons Attribution (CC BY) license (https:// creativecommons.org/licenses/by/ $4.0 /)$.

\begin{abstract}
Hepatitis C virus (HCV) is associated with various liver diseases. Chronic HCV infection is characterized by an abnormal host immune response. Therefore, it is speculated that to suppress $\mathrm{HCV}$, a well-regulated host immune response is necessary. 2-O-methylhonokiol was identified by the screening of anti-HCV compounds using Renilla luciferase assay in Huh 7.5/Con 1 genotype 1b replicon cells. Here, we investigated the mechanism by which 2-O-methylhonokiol treatment inhibits HCV replication using real-time PCR. Our data shows that treatment with 2-O-methylhonokiol activated innate immune responses via nuclear factor kappa-light-chain-enhancer of activated $B$ cells (NF-kB) pathway. Additionally, the immunoprecipitation result shows that treatment with 2-O-methylhonokiol augmented tumor necrosis factor receptor (TNFR)-associated factor 6 (TRAF6) by preventing p62 from binding to TRAF6, resulting in reduced autophagy caused by HCV. Finally, we reproduced our data with the conditioned media from 2-O-methylhonokiol-treated cells. These findings strongly suggest that 2-O-methylhonokiol enhances the host immune response and suppresses HCV replication via TRAF6-mediated NF-kB activation.
\end{abstract}

Keywords: 2-O-methylhonokiol; hepatitis C virus; nuclear factor kappa-light-chain-enhancer of activated B cells; innate immune response

\section{Introduction}

Hepatitis $\mathrm{C}$ virus (HCV) infection causes chronic liver diseases such as liver cirrhosis and liver cancer [1]. There are a total of seven genotypes of HCV [2], which include separate genotypes that are easily infected by race [3]. In particular, HCV genotype 1 has the highest incidence in the world of $46.2 \%$ [4]. Of the $53 \%$ of genotype 1 cases for which the subtype was specified, $99 \%$ were subtypes $1 \mathrm{a}$ and $1 \mathrm{~b}((31 \%$ and $68 \%)$, respectively) [4]. Currently, there is no available HCV vaccine, but the treatment of chronic HCV has made rapid progress. The existing standard treatment, pegylated-interferon (IFN) $\alpha+$ ribavirin combined therapy, has been reduced in utility due to severe side effects, along with relatively low therapeutic effects [5]. In recent years, direct acting antiviral (DAA) therapy has been used to suppress HCV replication by acting directly on certain areas of HCV non-structural proteins. Usually, two types of DAA with different modes of action are administered at the same time [6] or additional ribavirin are administered to patients who are difficult to treat. In addition, the rate of treatment caused by pangenotypic DAAs (glecaprevir/pibrentasvir) is over 98\% [7]. However, for patients which cirrhosis or retreatment, this treatment is highly likely to fail due to reinfection. Additionally, for young ages, pangenotypic DAA treatment faces high limitations [8]. Additionally, the cost of this treatment is high, and drug tolerance and persistent HCC risks after cure are present [5]. Therefore, many studies continue to address these issues [9]. 
Honokiol is a lignan isolated from the bark of the trees belonging to the genus, Magnolia [10]. Along with magnolol, 4-O-methylhonokiol, and obovatol, it has been identified as one of the chemical compounds in traditional herbal medicine. Herbal medicine has the advantage of being very cheap and having fewer side effects compared to conventional medication [11]. Recently, honokiol has been shown to inhibit HCV infection in vitro by targeting cell entry and replication. However, the mechanism by which honokiol inhibits HCV replication remains to be elucidated [12]. In addition, several honokiol derivatives have been identified, but their functional roles have not yet been explored, especially in HCV replication.

The human immune system develops in two ways: the innate immunity to immediately protect the spread and movement of foreign pathogens throughout the body; and the adaptive immunity, which takes several days to become protective, and remove a specific antigen [13]. Innate immune is a process that occurs immediately after infection, which directly forms proinflammatory cytokine and regulates adaptive immunity. Innate immunity is developed when pattern recognition receptors (PRRs), including retinoic acid-inducible gene I product (RIG-I)-like receptors (RLRs) and Toll-like receptors (TLRs), recognizes the pathogen-associated molecular patterns (PAMPs) of pathogens [14]. Two PRRs, RLRs, and TLRs are considered important to activate antiviral responses in an organism infected with HCV. Both recognize double-stranded RNA, essential in the HCV replication, and induce the synthesis of IFNs. RLRs signaling pathway activates NF-kB, the transcription factor for the expression of the inflammatory genes [15]. However, HCV has a mechanism that avoids the innate immune response of the host to keep the virus in the host cells [16]. For example, autophagy occurs within host cells to maintain HCV and suppress the host innate immune response by depleting the TRAF6, which is involved in the formation of proinflammatory cytokines [17]. In particular, NF-kB has been known as an important regulator for the inducible gene expression in the host immune system [18]. HCV infection inhibits TNF- $\alpha$-induced NF-kB activity [19]. In particular, HCV NS3 protein interacts with linear ubiquitin chain assembly complex (LUBAC) to suppress NF-kB activation [20]. Therefore, Increasing the host's immunity against HCV infection may be a good strategy.

Therefore, in this study, we investigated the mechanism of inhibitory effect of 2O-methylhonokiol, a derivative of honokiol, in HCV replication, using Huh 7.5/Con 1 genotype $1 \mathrm{~b}$ replicon cells. The aim of our study is to gain insight into HCV RNA replication mechanisms through induction of NF-kB, which is related to host innate immune response.

\section{Results}

\subsection{Inhibitory Effects of 2-O-Methylhonokiol on HCV Replication}

Renilla luciferase assays were performed in Huh 7.5/Con 1 genotype $1 \mathrm{~b}$ replicon cells in the absence or presence of 80 compounds with antioxidant properties to identify inhibitors of HCV replication, since HCV genotype $1 \mathrm{~b}$ had the highest incidence (Figure 1a). As a result of repeated quantitative analysis of $\mathrm{HCV}$ replication, it was confirmed that 2-O-methylhonokiol inhibited $\mathrm{HCV}$ replication by more than 50\% relative to that in equal volume DMSO-treated cells (Figure 1b). Figure 1c shows the structure of 2-O-methylhonokiol. The cytotoxicity and anti-HCV efficacy of 2-O-methylhonokiol were evaluated. As a result of MTS analysis, 2-O-mehtylhonokiol did not significantly affect cell viability up to a concentration of $50 \mu \mathrm{M}$ for $24 \mathrm{~h}$ (Figure 1d). However, Huh 7.5/Con 1 genotype $1 \mathrm{~b}$ replicon at a concentration of $50 \mu \mathrm{M}$ was suppressed by more than $50 \%$, compared with that in equal volume DMSO-treated-cells (Figure 1e). Therefore, the following experiments were performed with $50 \mu \mathrm{M}$ 2-O-methylhonokiol. To confirm the inhibitory effect of 2-O-methylhonokiol on HCV replication, expressions of HCV non-structural proteins, namely NS3, NS4B, NS5A, and NS5B, were analyzed by Western blot assay. As expected, treatment with 2-O-methylhonokiol significantly suppressed the expression of viral non-structural proteins, especially at $48 \mathrm{~h}$, while there was no significant change in protein expression at $24 \mathrm{~h}$ (Figure 1f). 


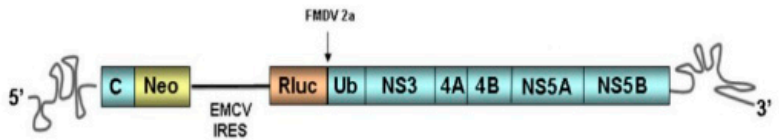

(a)

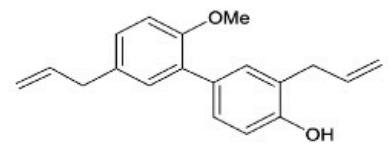

(c)

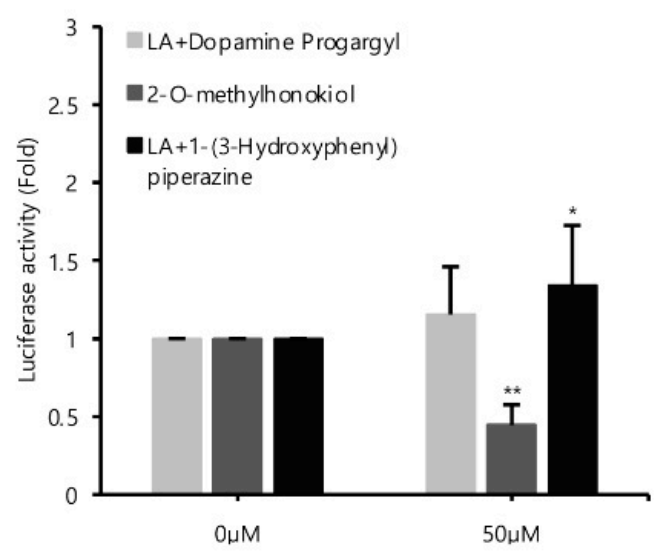

(b)

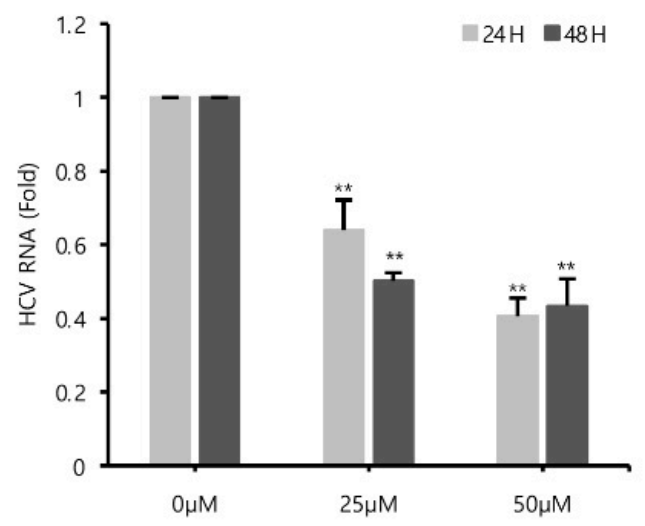

(e)

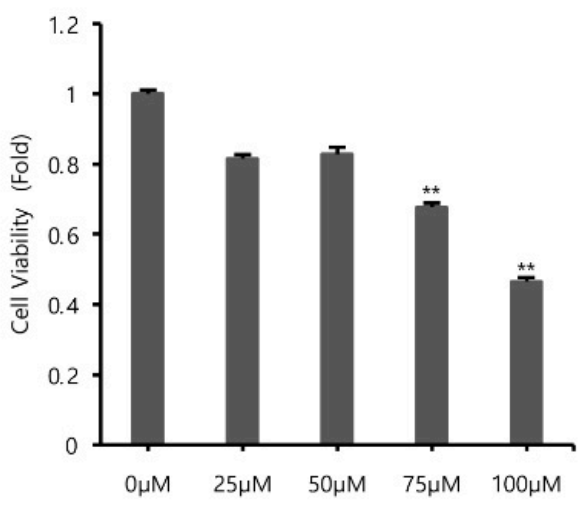

(d)

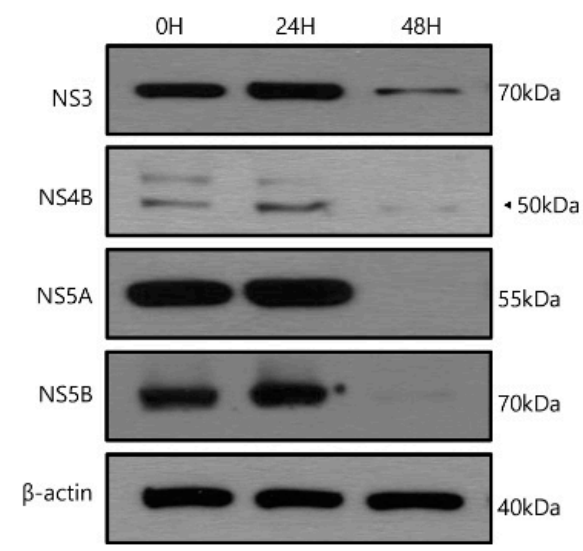

$(f)$

Figure 1. Effects of 2-O-methylhonokiol on HCV replication. (a) The structure of Huh7.5/Con1 replicon. (b) Huh7.5/Con1 cells were treated with three different promising compounds of $50 \mu \mathrm{M}$ each for $24 \mathrm{~h}$. HCV replication was measured by Renilla luciferase assays. (c) The chemical structure of 2-O-methylhonokiol. (d) Huh7.5/Con1 cells were treated with the indicated concentrations of 2-O-methylhonokiol for $24 \mathrm{~h}$. Cell viability was measured by MTS assay. (e) After treatment with 25 or $50 \mu \mathrm{M}$ of 2-O-methylhonokiol for 24 or $48 \mathrm{~h}$, HCV RNA levels were measured by qRT-PCR. (f) Western blotting analysis of HCV non-structural protein (NS3, NS4B, NS4A, and NS5B) using Huh7.5/Con1 cells treated with $50 \mu \mathrm{M}$ 2-O-methylhonokiol for (24 or 48) h. In each experiment, $0 \mathrm{H}$ or $0 \mu \mathrm{M}$ means a control. The values are shown as the mean $\pm \mathrm{SD}$ of three independent experiments. ${ }^{*} p<0.05,{ }^{* *} p<0.01$ versus untreated control.

\subsection{Comparison of 2-O-Methylhonokiol and Honokiol on Cytotoxicity and $\mathrm{HCV}$ Replication Inhibition}

Since honokiol was already reported to inhibit HCV replication [12], we compared the effects of honokiol and 2-O-methylhonokiol on cytotoxicity and anti-HCV activity. Cell viability was measured by MTS assay, after Huh7.5/Con1 cells and Huh7 cells were treated with various concentrations of honokiol and 2-O-methylhonokiol for 24 or $48 \mathrm{~h}$. When Huh7.5/con1 cells were treated with $50 \mu \mathrm{M}$ for $24 \mathrm{~h}$, 2-O-mehtylhonokiol treatment showed about $20 \%$ higher cell viability compared to honokiol treatment. At 48 h treat- 
ment, 2-O-methylhonokiol treatment showed about $40 \%$ higher cell viability compared to honokiol treatment. Therefore, In Huh7.5/con1 cells, 2-O-methylhonokiol was less toxic than honokiol (Figure 2a). On the other hand, there was no significant change in cell viability in Huh7 cells treated for $24 \mathrm{~h}$. However, in Huh7 cells treated with $50 \mu \mathrm{M}$ for 48 h, 2-O-methylhonokiol was less toxic by approximately $20 \%$ than honokiol (Figure $2 \mathrm{~b}$ ). Next, we analyzed HCV replication with Renilla luciferase assay to compare the difference of anti-HCV activity of two compounds. There was little difference in the ability of the honokiol and 2-O-methylhonokiol to suppress HCV replication (Figure 2c). Thus, we concluded that 2-O-methylhonokiol is a more promising candidate than honokiol as an anti-HCV drug.

\subsection{2-O-Methylhonokiol Suppresses HCV Replication through NF-kB Activation}

Next, we investigated how 2-O-methylhonokiol affects NF-kB activity and the host innate immune system, and compared with honokiol. First, we monitored whether honokiol and 2-O-methylhonokiol activates NF-kB by qRT-PCR and immunoblotting analysis.

Figure 3a shows that while 2-O-mehtylhonokiol treatment effectively increased the RelA/p65 mRNA and protein levels by about (2-3)-fold, honokiol treatment did not change the RelA/p65 mRNA and protein levels. While 2-O-methylhonokiol treatment effectively increased the nuclear RelA/p65 pool, which indicates nuclear translocation of RelA/p65 (Figure 3b, right; and Figure 3c), honokiol did not increase the nuclear RelA/p65 pool (Figure 3b, left). Therefore, we found that the difference between honokiol and 2-O-methylhonokiol in inhibiting HCV replication is whether they cause NF-kB activation.

To confirm the nuclear translocation of RelA/p65 subunit of NF-kB, we used NF-kBluciferase reporter assay in Huh7.5/Con1 cells after the 2-O-methylhonokiol treatment. When treated with 2-O-methylhonokiol for $48 \mathrm{~h}$, we observed almost 15-folds increase in NF-kB-luciferase activity, compared to equal volume DMSO-treated cells (Figure 3d).

To further analyze the role of NF-kB activation in the inhibitory effect of 2-O-methylhonokiol in HCV replication, RelA/p65 knockdown by siRNA experiments was utilized. Huh 7.5/Con 1 genotype $1 \mathrm{~b}$ replicon cells were transfected with si-RelA/p65 for $48 \mathrm{~h}$, and RelA/p65 knockdown efficiency was verified by Western blotting (Figure 3e). Then HCV RNA replication was analyzed in RelA/p65 knockdown for $48 \mathrm{~h}$, after treatment with 2-O-methylhonokiol for 24 or $48 \mathrm{~h}$. Figure $3 \mathrm{f}$ shows that, as expected, 2-O-methylhonokiol significantly suppressed HCV replication in si-Con. However, RelA/p65 knockdown abolished the suppressive effects of 2-O-methylhonokiol in HCV replication. Interestingly, compared to siCon, HCV replication in NF-kb/p65-knockdown cells were increased by about (2-5)-fold, independently of 2-O-methylhonokiol. This was highlighted by the difference between HCV RNA levels in siCon/2-methylhonokiol-treated versus siRelA/p65/2-mehtylhonokiol-treated HCV cells, suggesting that NF-kB(p65) mediated $\mathrm{HCV}$ replication. So, our data suggest that 2-O-methylhonokiol inhibits HCV replication through NF-kB activation.

\subsection{2-O-Methylhonokiol Enhances TRAF6-Mediated NF-kB Activation}

TRAF6 is an important signaling molecule that mediates the activation of NF-kB and is depleted by HCV [17]. Therefore, we hypothesized that 2-O-methylhonokiol may reactivate TRAF6-mediated NF-kB signaling pathway. First, we monitored the expression levels of TRAF6 mRNA and protein level after treatment with 2-O-methylhonokiol for 24 or $48 \mathrm{~h}$. Figure $4 \mathrm{a}$ shows that the TRAF6 mRNA levels were not significantly affected by treatment with 2-O-methylhonokiol, compared to equal volume DMSO-treated cells; however, treatment with 2-O-methylhonokiol significantly increased the expression levels of TRAF6 protein levels, compared to equal volume DMSO-treated cells (Figure 4b). 


\section{Huh7.5/con1 cell}
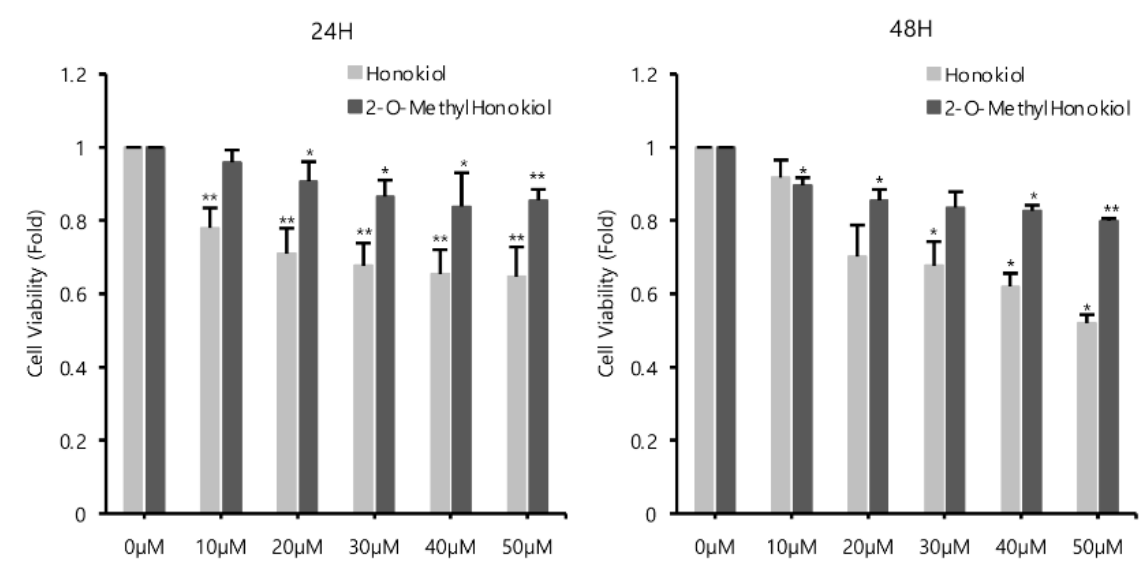

(a)

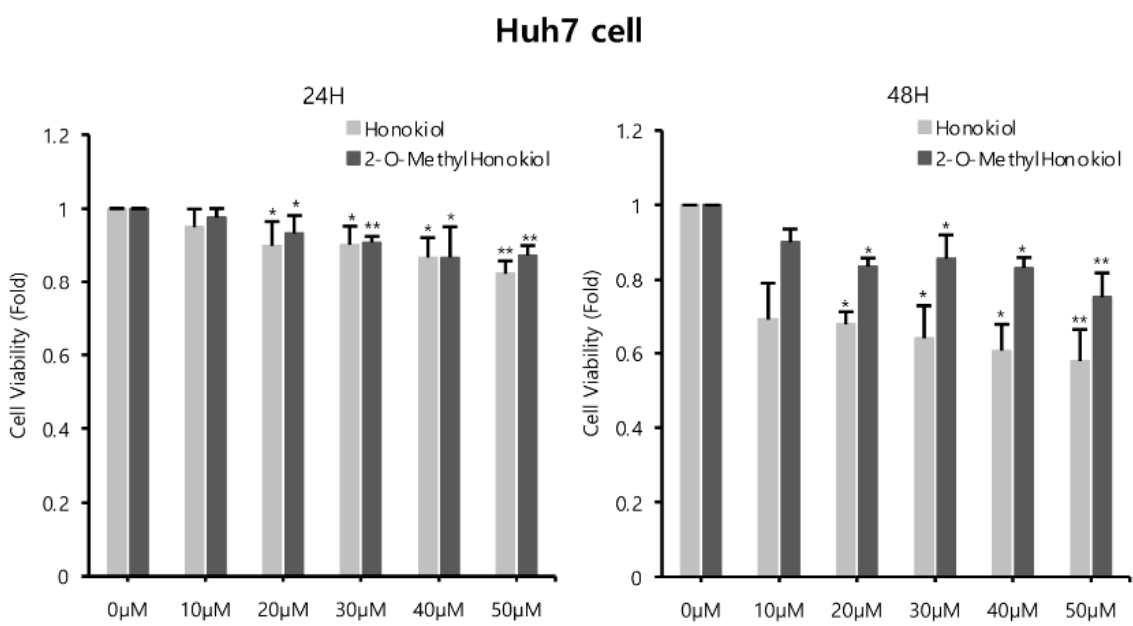

(b)

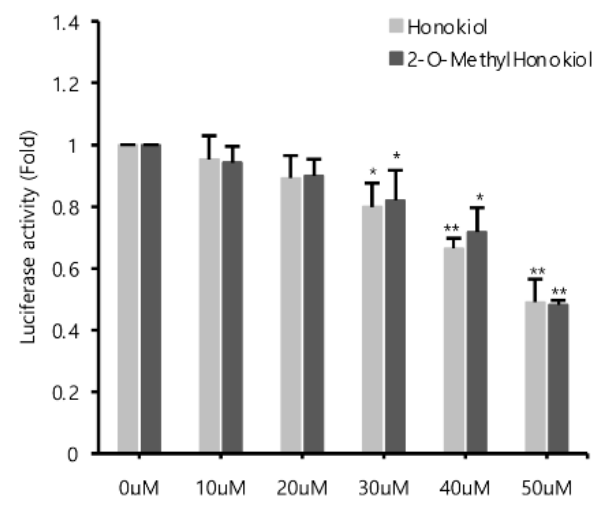

(c)

Figure 2. Comparison of 2-O-methylhonokiol and honokiol on cytotoxicity and HCV replication inhibition. (a) Huh7.5/Con1 cells and (b) Huh7 cells were treated with honokiol and 2-O-mehtylhonokiol at the indicated doses for 24 or $48 \mathrm{~h}$. Cell viability was measured by MTS assay. (c) After Huh7.5/Con1 cells were treated with honokiol or 2-O-methylhonokiol at the indicated doses for $24 \mathrm{~h}$, the levels of HCV RNA were measured by Renilla luciferase assay. In each experiment, $0 \mu \mathrm{M}$ means a control. The values are shown as the mean $\pm \mathrm{SD}$ of three independent experiments. ${ }^{*} p<0.05,{ }^{* *} p<0.01$ versus untreated control. 


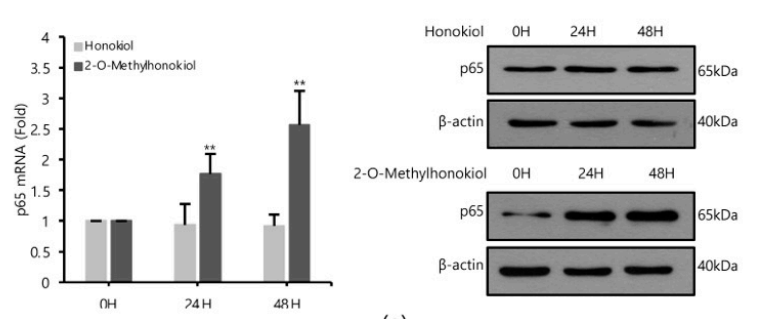

(a)
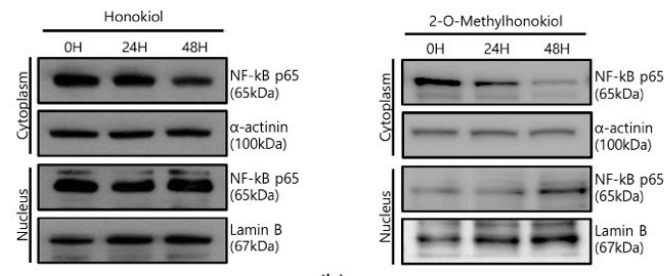

(b)

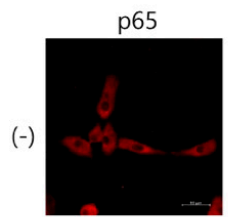

DAPI
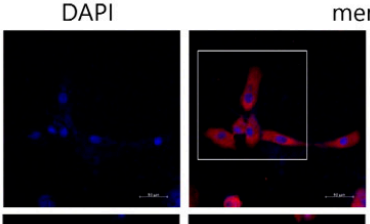

merge
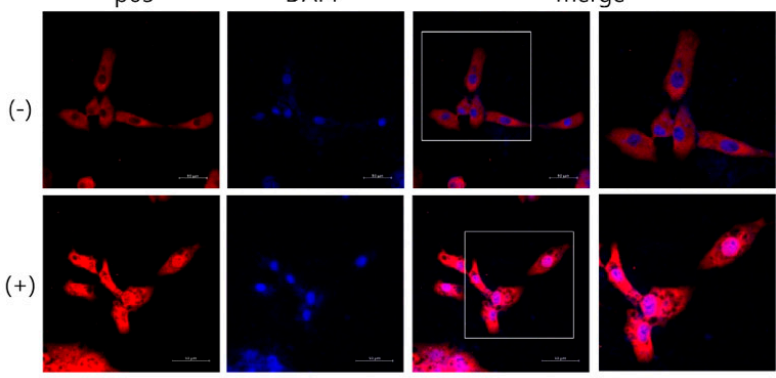

(c)
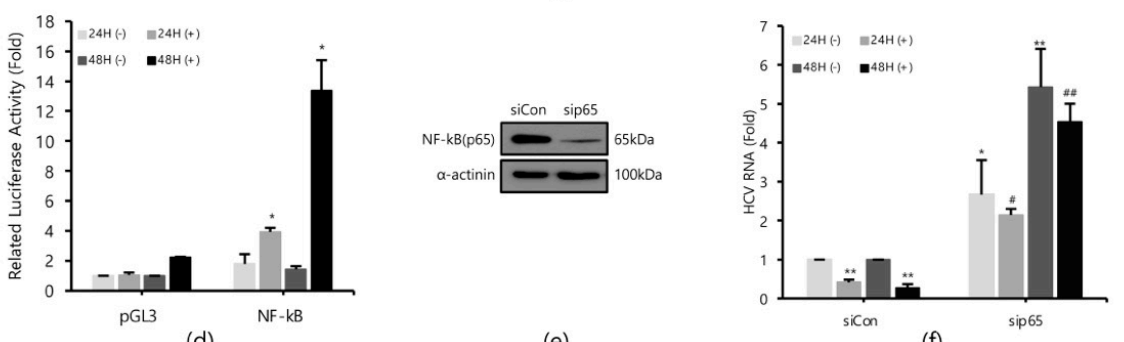

Figure 3. 2-O-methylhonokiol inhibits HCV replication via NF-kB activation, but honokiol does not. (a) After treatment of $50 \mu \mathrm{M}$ of 2-O-methylhonokiol and honokiol for 24 or $48 \mathrm{~h}$, p65 mRNA levels were measured by qRT-PCR (left), and Western blotting analysis of p65 protein (right), using Huh7.5/Con1 cells. (b) Cytosol or nuclear fractions were isolated and analyzed by Western blotting in huh7.5/Con1 cells treated with $50 \mu \mathrm{M}$ 2-O-methylhonokiol (right), and honokiol (left), for 24 or $48 \mathrm{~h}$. Lamin B (nuclear marker) and $\alpha$-actinin (cytosolic marker) immunoblotting were also included to confirm the purity of the nuclear and cytosolic fractions, respectively. (c) Huh7.5/Con1 cells were treated with or without $50 \mu \mathrm{M}$ 2-O-methylhonokiol for $24 \mathrm{~h}$, and then subjected to immunofluorescence with anti-p65 antibody (red). DAPI (blue) was used for nuclear staining. Scale bar $=50 \mu \mathrm{m}$. (d) Huh7.5/Con1 cells were transfected with pGL3-Luc-NF-kB plasmid or the empty pGL3 vector for $24 \mathrm{~h}$. Luciferase activity was measured after treatment with or without $50 \mu \mathrm{M}$ 2-O-methylHonokiol for 24 or $48 \mathrm{~h}$. Luciferase activity was expressed relative to that in DMSOtreated cells. (e) Expression of NF-kB(p65) protein in control (si-Con) and NF-kB(p65)-interfered (si-RelA/p65) Huh7.5/Con1 cells was shown. (f) After transfection with si-Con or si-RelA/p65 for $48 \mathrm{~h}, \mathrm{Huh} 7.5 /$ Con 1 cells were treated with or without $50 \mu \mathrm{M}$ 2-O-methylhonokiol for 24 or $48 \mathrm{~h}$. The HCV RNA level were then analyzed by qRT-PCR. The values are shown as the mean \pm SD of five independent experiments. ${ }^{*} p<0.05,{ }^{* *} p<0.01$ versus untreated control or versus the untreated siCon-transfected control; \# $p<0.05$, \#\# $p<0.01$ versus the 2-O-methylhonokiol-treated, siCon-transfected control; one-way ANOVA with Tukey's multiple comparisons test. 


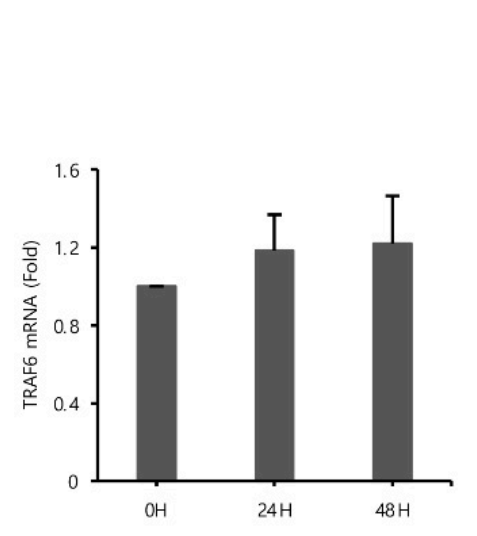

(a)

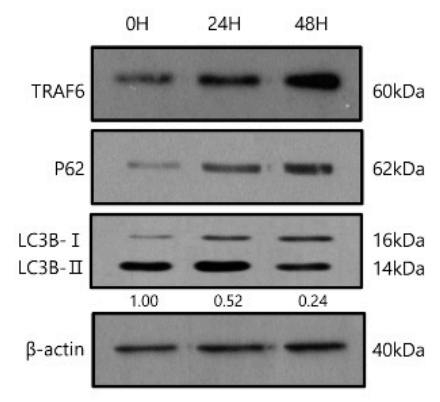

(b)

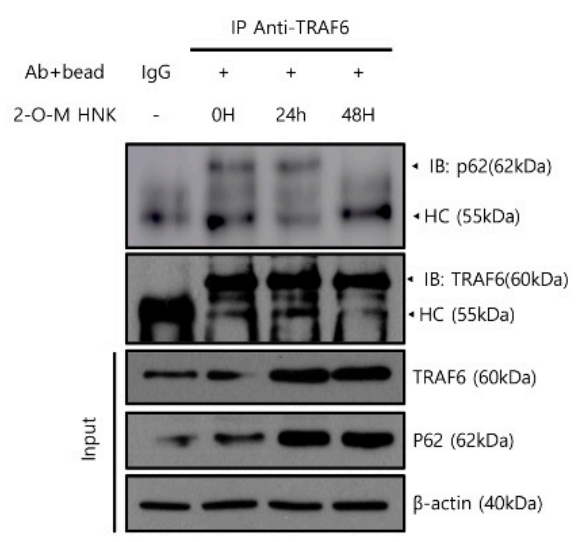

(c)

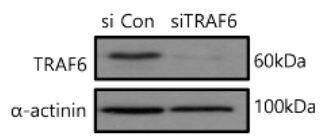

(d)

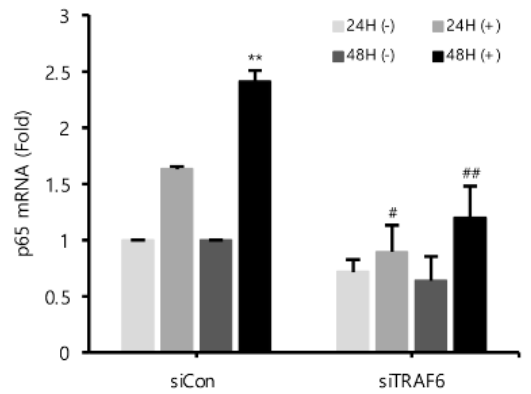

(e)

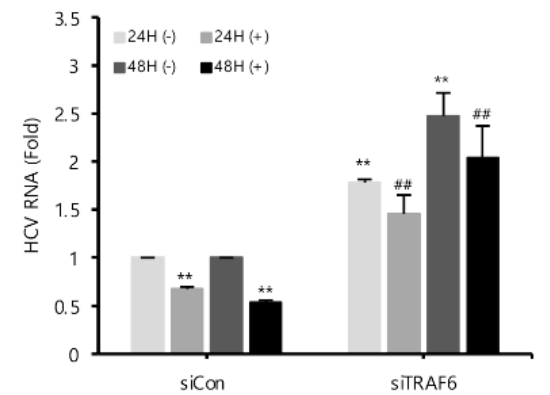

(f)

Figure 4. 2-O-methylhonokiol enhances TFAF6-mediated NF-kB activation. After treatment with $50 \mu \mathrm{M} 2-\mathrm{O}-\mathrm{methylhonokiol}$ for 24 or $48 \mathrm{~h}$, (a) TRAF6 mRNA levels were analyzed by qRT-PCR, and (b) the protein levels of TRAF6, p62, and LC3B were analyzed by Western blotting. (c) Immunoprecipitation was performed with Huh7.5-Con1 cells with or without $50 \mu \mathrm{M}$ 2-O-methylhonokiol for 24 or $48 \mathrm{~h}$ using antibodies against TRAF6, and precipitated protein complexes were probed with anti-p62 antibodies. The total cell lysates were also used for immunoblotting to serve as the input control. HC, antibody heavy chain; 2-O-M HNK, 2-O-methylhonokiol. (d) Expression of TRAF6 protein in control (si-Con) and TRAF6-interfered (si-TRAF6) Huh7.5/Con1 cells is shown. After transfection with si-Con or si-TRAF6 for 48 h, Huh7.5/Con cells were treated with or without $50 \mu \mathrm{M}$ 2-O-methylhonokiol for 24 or $48 \mathrm{~h}$. (e) The mRNA level of p65 and (f) the HCV RNA level were then analyzed by qRT-PCR. The mRNA level of p65 and HCV RNA level were normalized against $\beta$-actin RNA. In each experiment, ' $0 \mathrm{H}^{\prime}$ means a DMSO control. The values are shown as the mean $\pm \mathrm{SD}$ of five independent experiments. ${ }^{* *} p<0.01$ versus untreated control or versus the untreated siCon-transfected control; \# $p<0.05$, \#\# $p<0.01$ versus the 2-O-methylhonokiol-treated, siCon- transfected control or versus CQ or 2-O-M HNK; one-way ANOVA with Tukey's multiple comparisons test.

To confirm our data, we measured the level of p65 mRNA expression and the level of HCV replication in TRAF6 knockdown. TRAF6 knockdown was verified by Western blotting (Figure 4d). As expected, treatment with 2-O-methylhonokiol activated the transcription of RelA/p65 by 2 folds in si-Con. However, the activated RelA/p65 transcription was abolished in TRAF6 knockdown (Figure 4e). Additionally, we confirmed that the increased levels of NF-kB(p65) mRNA by 2-O-methylhonokiol are more likely due to an increase in transcription itself, rather than mRNA stability (Figure S1 of the Supplementary Information (SI)). Figure $4 \mathrm{f}$ shows that the suppressed HCV replication by 2-O-methylhonokiol was reactivated by (2-3)-fold in TRAF6 knockdown. Interestingly, compared to siCon, HCV RNA replication was increased independently of 2-O-methylhonokiol by about (1.5-2)fold in TRAF6-knockdown cells. Overall, our results suggested that 2-O-methylhonokiol inhibits HCV RNA replication through activation of TRAF6-mediated NF-kB pathway.

Several studies have shown that HCV replication induces LC3II expression and reduces the expression of p62/SQSTM1, an autophagy adapter that interacts with TRAF6 
and LC3, leading to autophagy [21-25]. Therefore, we monitored whether treatment with 2-O-methylhonokiol suppresses autophagy by Western blotting. Figure 4 b shows that p62/SQSTM1 was induced by treatment with 2-O-methylhonokiol. Additionally, the LC3II/LC3I ratio decreased, suggesting that treatment with 2-O-methylhonokiol diminishes autophagy. p62 has been reported to bind to TRAF6 in HCV-infected cells to proceed with autophagic degradation of TRAF6 [17]. Immunoprecipitation was performed to investigate the role of 2-O-methylhonokiol in p62-TRAF6 interaction. We found that the physical binding of p62 and TRAF6 was abolished by 2-O-methylhonokiol treatment, especially at $48 \mathrm{~h}$, suggesting that treatment with 2-O-methylhonokiol may decrease autophagy (Figure 4c). Our data showed that treatment with 2-O-methylhonokiol increased TRAF6 by preventing p62 from binding to TRAF6. Then, we tested the effect of 2-O-mehtylhonokiol on viral replication in the presence of autophagy inhibitors. Additionally, we showed that combination treatment with 2-O-methylhonokiol and chloroquine, a well-known autophagy inhibitor [26], reduced HCV replication more than each treatment, suggesting that 2-O-methylhonokiol displays a synergistic effect with chloroquine (Figures S1 and S2). Finally, 2-O-methylhonokiol directly affected p62 and LC3, inhibiting autophagy that occurs during HCV replication. We also found that HCV replication was inhibited by activation of the TRAF6-mediated NF-kB by inhibiting depletion of the TRAF6, which became autophagic degradation by p62 in HCV replication.

\subsection{2-O-Methylhonokiol Stimulates Innate Immune Responses}

Type I interferons (IFNs) are a family of primitive cytokines that respond to infection with various pathogens, such as $\operatorname{HCV}[27,28]$. HCV replication has been reported to be inhibited when IFN- $\alpha$ is upregulated [29]. Expressions of innate immune responserelated genes, such as protein kinase $\mathrm{R}$ (PKR) [30] and myxovirus resistance protein 1 (MxA) [31,32] induced by IFNs, also suppress HCV replication. To identify the effects of 2-O-methylhonokiol on IFNs and IFNs down-stream effectors in inhibition of HCV replication, mRNA expressions of IFN- $\alpha$, IFN- $\beta$, MxA, and PKR genes were measured by qRT-PCR. Figure 5a shows that 2-O-methylhonokiol upregulated mRNA expressions of IFN- $\alpha$, IFN- $\beta$, MxA, and PKR genes, compared with non-treated, especially for $48 \mathrm{~h}$. Consistently, 2-O-methylhonokiol treatment induced IFN- $\alpha$ secretion 2-3 times, compared to no treatment (Figure $5 \mathrm{~d}$ ). In order to confirm the results, we measured the expression of IFN- $\alpha$ by qRT-PCR or IFN- $\alpha$ ELISA in RelA/p65 knockdown. Figure 5b shows the qRT-PCR analysis that revealed that the upregulated mRNA expression of IFN- $\alpha$ was abolished in RelA/p65 knockdown. Induced secretion of IFN- $\alpha$ also was also abolished in RelA/p65 knockdown (Figure 5e). Altogether, our results suggest that treatment with 2-O-methylhonokiol inhibits HCV replication by activating innate immune responses via the NF-kB pathway.

\subsection{Conditioned Media from 2-O-Methylhonokiol-Trated Cells also Inhibit HCV Replication}

Finally, in order to confirm that 2-O-methylhonokiol stimulates innate immune responses to inhibit HCV replication, we collected the supernatants in the conditioned medium from Huh7.5/Con1 cells and examined their effects on HCV replication. Compared to cells treated with the equal volume of DMSO, conditioned media from 2-Omethylhonokiol-treated cells significantly inhibited HCV replication by $50 \%$ and increased mRNA levels of IFN- $\alpha$, IFN- $\beta$, PKR, and MxA by about (2-3)-fold (Figure 6b,c). Additionally, we used RelA/p65-knockdown cells to confirm that 2-O-methylhonokiol activates NF-kB signal to inhibit HCV replication. Figure $6 \mathrm{~d}$ shows that treatment with the conditioned media significantly reduced HCV replication in si-Control. However, HCV replication was increased in RelA/p65 knockdown. Moreover, we could not find any transcriptional upregulation of IFN- $\alpha$ in p65 knockdown, especially for $48 \mathrm{~h}$ (Figure 6e). All these together, we concluded that treatment with 2-O-methylhonokiol inhibits HCV replication by activating innate immune responses via the NF-kB pathway (Figure 7). 


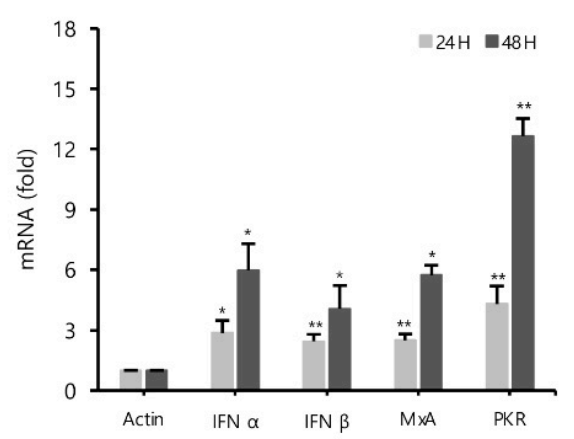

(a)

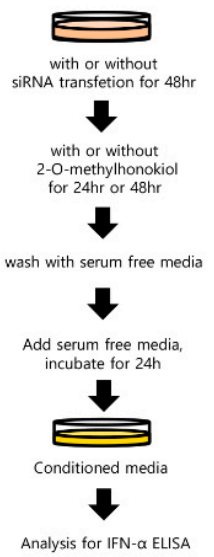

(c)

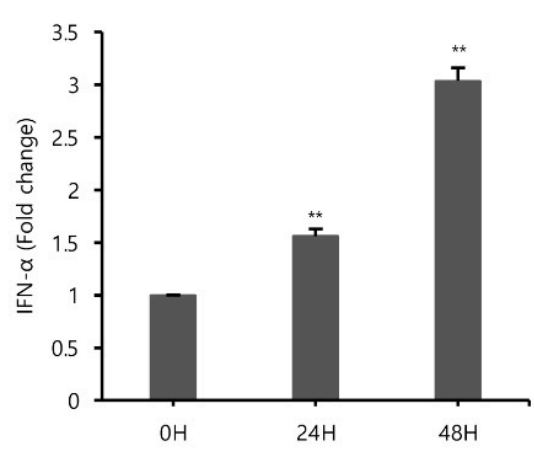

(d)

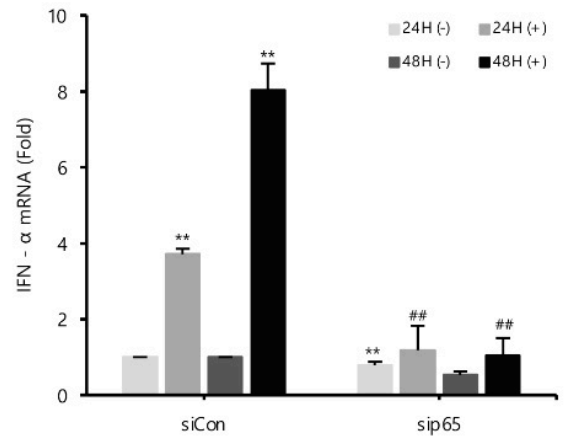

(b)

Figure 5. 2-O-methylhonokiol activates innate immune response. (a) The mRNA levels of IFN- $\alpha$, IFN- $\beta$, MxA, and PKR in Huh7.5/Con1 cells treated with $50 \mu \mathrm{M}$ 2-O-methylhonokiol for 24 or $48 \mathrm{~h}$ were analyzed by qRT-PCR. After transfection with si-Con or si-RelA/p65 for 48 h, Huh7.5/Con1 cells were treated with or without $50 \mu \mathrm{M}$ 2-O-methylhonokiol for (24 or 48) h. (b) The mRNA level of IFN- $\alpha$ in treated cells was confirmed through qRT-PCR, and (e) the amount of IFN- $\alpha$ secretion was confirmed through ELISA kits. (c) Schematic of the ELISA process. (d) huh7.5/Con 1 cells were treated with $50 \mu \mathrm{M}$ 2-O-methylhonokiol for 24 or $48 \mathrm{~h}$. After incubation in serum-free DMEM for $24 \mathrm{~h}$, the supernatants were harvested, and analyzed using IFN- $\alpha$ ELISA kits. The values are shown as the mean $\pm \mathrm{SD}$ of five independent experiments. ${ }^{*} p<0.05,{ }^{* *} p<0.01$ versus untreated control or versus the untreated siCon-transfected control; \#\# $p<0.01$ versus the 2-O-methylhonokiol-treated, siCon-transfected control; one-way ANOVA with Tukey's multiple comparisons test. 


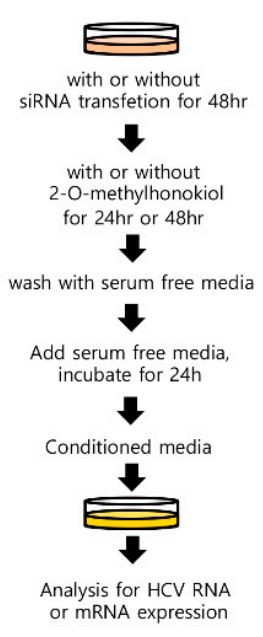

(a)

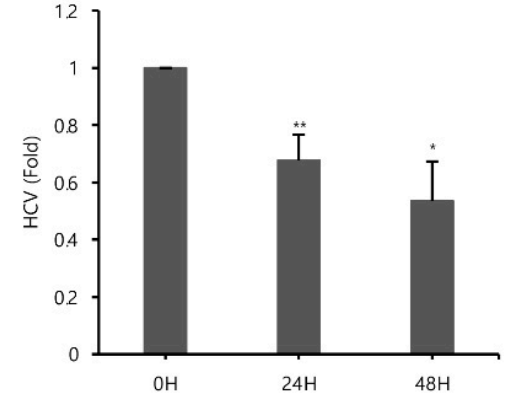

(b)

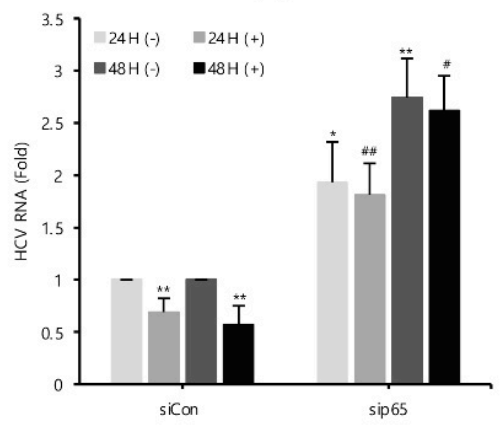

(d)

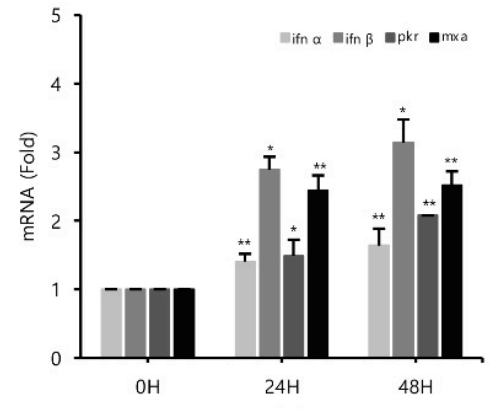

(c)

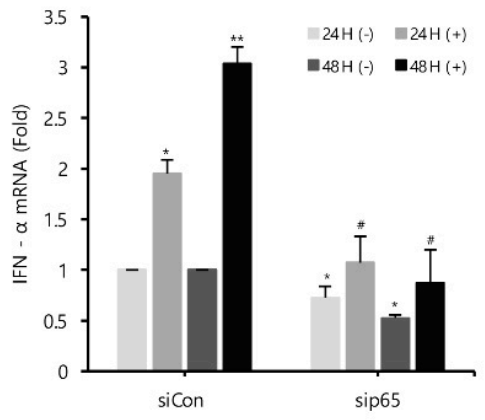

(e)

Figure 6. Conditioned media derived from 2-O-methylhonokiol-treated cells also suppresses HCV replication and activates innate immune responses. (a) Schematic of the experimental process. The conditioned medium cells were collected from the cell lines treated with $50 \mu \mathrm{M} 2-\mathrm{O}-$-methylhonokiol. The levels of (b) HCV RNA, and (c) the indicated mRNAs, were measured by qRT-PCR, using the conditioned media-treated cell lines. After transfection with si-Con or si-RelA/p65 for $48 \mathrm{~h}$, Huh7.5/Con1 cells were treated with or without $50 \mu \mathrm{M}$ 2-O-methylhonokiol for 24 or $48 \mathrm{~h}$. The levels of (d) HCV RNA, and (e) IFN- $\alpha$ mRNA, were then analyzed by qRT-PCR, after treatment with $50 \mu \mathrm{M}$ 2-O-methylhonokiol for (24 or 48) h. The values are shown as the mean $\pm \mathrm{SD}$ of three independent experiments. ${ }^{*} p<0.05,{ }^{* *} p<0.01$ versus untreated control, or versus the untreated siCon-transfected control; \# $p<0.05$, \#\# $p<0.01$ versus the 2-O-methylhonokiol-treated, siCon-transfected control; one-way ANOVA with Tukey's multiple comparisons test.

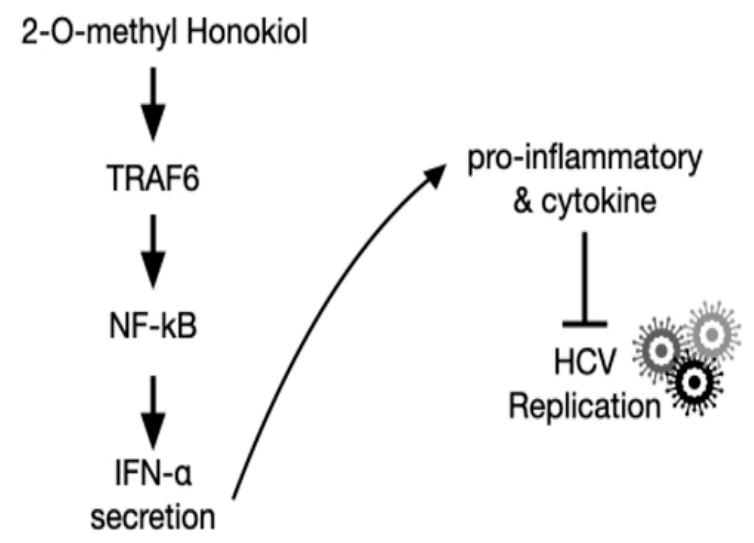

Figure 7. Schematic of the mechanism by which 2-O-methylhonokiol suppresses HCV replication.

\section{Discussion}

In this paper, we demonstrated that 2-O-methylhonokiol suppresses $\mathrm{HCV}$ replication through NF-kB activation and induces host innate immune responses. Honokiol has been reported to have the effect of inhibiting HCV replication, although the mechanism is still unclear [12]. 
The compound schematic in Figure 1c shows that the 2-O-methylhonokiol is one of honokiol derivatives. Honokiol is an herbal medicine derived from several species of magnolia native to many parts of the world. Medicinal plants have proven that they can be used to cope with many diseases, including cancer and viral diseases [33]. Herbal medicines are easily accessible to the public in terms of price, and are much safer than modern synthetic drugs [11]. Furthermore, herbal medicine still holds an important position in the modern pharmaceutical industry, due to its small side effects, and synergies from combinations of compounds [34]. Although herbal medicine is still less common in the United States and Europe, much more research is being conducted since scientific evidence of the effectiveness has become more widely available [35]. However, there are still shortcomings, such as the lack of drug effects due to low in-body absorption rates, and the complexity of drug discovery, such as the inability to purify individual ingredients on a sufficient scale [33]. 2-O-methylhonokiol has less cytotoxicity than honokiol, while 2-Omethylhonokiol exhibits almost the same inhibitory effects as honokiol in HCV replication (Figure 2). Therefore, our data suggest that as anti-HCV drug, 2-O-methylhonokiol may be a more beneficial treatment than honokiol.

Interestingly, we showed that 2-O-methylhonokiol treatment activated NF-kB activation for its antiviral activity in Huh 7.5/Con 1 genotype $1 \mathrm{~b}$ replicon, and confirmed it using RelA/p65 knockdown cells (Figure 3). However, NF-kB pathway was not altered in honokiol-mediated inhibition of HCV replication. This suggested that the methyl group of 2-O-methylhonokiol may play an important role in NF-kB activation, although further studies are needed to differentiate the inhibitory mechanisms of honokiol and 2-O-methylhonokiol in HCV replication. NF-kB pathway was originally reported as a host factor supporting HCV subgenomic replicon replication in Huh 7.5 cells [36]. However, it was recently reported that NF-kB inactivation resulted in the enhanced HCV replication of Huh 7.5/Con1b replicon [37] and HCV1a infected Huh7.5.1 cells [38]. While there are few reports about 2-O-methylhonokiol, various results have recently been published on the regulation of NF-kB by honokiol. Honokiol was reported to suppress NF-kB activated by carcinogens and inflammatory stimuli through the suppression of Akt and activation of IKK in many cell lines [39]. In contrast, it was reported that honokiol treatment did not alter NF-kB pathway in dengue virus infected Huh7 cells [40]. Moreover, honokiol was also reported to efficiently motivate the NF-kB pathway by 17 -fold for antiviral activity in grass carp reovirus infected-C. idella kidney cells [41]. Therefore, there has been controversy over the role of honokiol in the NF-kB pathway. The reason for this discrepancy is unknown, but it may be attributable to difference in cell types and infected viruses.

In addition, TRAF6 is an important mediator for the activation of NF-kB, leading to the expression of antiviral cytokines [17,42-45]. Figure 4b shows that treatment with 2-Omethylhonokiol increased TRAF6 proteins by preventing $\mathrm{p} 62$ from binding to TRAF6. We showed that TRAF6 mediated the mechanism by which 2-O-methylhonokiol activates NFkB pathway (Figure 4e). Moreover, HCV replication was increased in TRAF6 knockdown, suggesting that TRAF6 may be directly related to HCV replications (Figure 4f).

Autophagy is known to eliminate the infection of bacterial pathogens [46] and virus [47]. However, HCV-induced autophagy increases HCV replication, rather than inhibiting it [48]. In HCV-induced autophagy, it was reported that p62, which is important for selective autophagy, increases HCV replication by degrading TRAF6 [17]. Figure 4b shows that 2-O-methylhonokiol treatment prevented the degradation of p62, and reduced LC3II/LC3I ratio to inhibit HCV-induced autophagy.

In addition, we showed that 2-O-methylhonokiol upregulated innate immune response genes, such as IFNs, MxA, and PKR (Figure 5). Finally, we confirmed our data using conditioned media from 2-O-methylhonokiol-treated cell lines (Figure 6). Our findings suggest that 2-O-methylhonokiol might be a promising candidate to enhance host innate immunity against HCV through NF-kB pathway. 


\section{Materials and Methods}

\subsection{Cells and Compounds}

Huh7.5 cells expressing the HCV genotype $1 \mathrm{~b}$ subgenomic replicon (Con1/SG-Neo(I)hRluc2aUb) were cultured in Dulbecco's modified Eagle's medium (DMEM) with 10\% fetal bovine serum, $100 \mathrm{U} / \mathrm{mL}$ penicillin-streptomycin, $2 \mathrm{mM}$ non-essential amino acid (Gibco, Grand Island, NY, USA), and $0.3 \mathrm{mg} / \mathrm{mL}$ geneticin (Thermo Fisher Scientific, Waltham, MA, USA) [29]. Huh7 cells were cultured in RPMI1640 supplemented with $10 \%$ FBS. All cells were cultured in a humidified atmosphere $\left(5 \% \mathrm{CO}_{2}, 37^{\circ} \mathrm{C}\right)$. The antioxidant compounds, including 2-O-methylhonokiol, were kindly gifted by Dr. Jongho Park, Han-bat University, Daejeon, Korea. Chloroquine was purchased from Sigma-Aldrich (catalog no. C662825G; Sigma-Aldrich, St. Louis, MO, USA). 2-O-methylhonokiol and chloroquine were dissolved in dimethylsulfoxide (DMSO). Stock solutions of honokiol, 2-O-methylhonokiol, and chloroquine (final concentration, $50 \mathrm{mM}$ ) was prepared in DMSO, stored at $-20^{\circ} \mathrm{C}$, and diluted with fresh complete medium immediately before use. An equal volume of DMSO (final concentration $<0.1 \%$ ) was always used as a control.

\subsection{Plasmids, siRNAs Transfection}

X-treamgene HP DNA transfection reagents were used according to the manufacturer's instruction (catalog no. 06366546 001; Roche, Swiss). The following siRNA were purchased from Dharmarcon (Dharmacon, Denver, CO, USA): siGenome human RelA (D-003533-04-0010), siGenome human TRAF6 (D-004712-04-0020), and control siRNA (D-001210-02-20). We transfected with each siRNA(100 nM) for $48 \mathrm{~h}$ using Viromer BLUE transfection reagent (catalog no. VB-01LB-00; lipocalyx, Germany), according to the manufacturer's instructions.

\subsection{Cell Viability Assay}

Cells were seeded in 24-well plate. After $24 \mathrm{~h}$, the cells were incubated with varying concentrations of the indicated compounds for 24 or $48 \mathrm{~h}$. After each time treatment, Cell Viability was measured by using Chromo- $\mathrm{CK}^{\mathrm{TM}}$ Cell Viability Assay (MTS) reagent (monobio, Seoul, Korea; catalog no. CH-10000), which was added to the medium for $1 \mathrm{~h}$ at $37^{\circ} \mathrm{C}$. Absorbance was measured with Microplate Reader (Molecular Device, Sunnyvale, CA, USA) at $450 \mathrm{~nm}$.

\subsection{Luciferase Reporter Assay}

Renilla luciferase assay: Briefly, Huh7.5/Con1 Cells were plated at $1 \times 10^{5}$ per well in 24-well plates. After $24 \mathrm{~h}$, the cells were treated the indicated compounds for $24 \mathrm{~h}$. After treatment, the cells were washed with 1X PBS. Then $200 \mu \mathrm{L}$ of 1X Renilla luciferase assay lysis buffer was added to each culture well, and the culture plates were placed on orbital shaker with gentle shaking for $15 \mathrm{~min}$ at room temperature. The cell lysate was transferred to a $1.5 \mathrm{~mL}$ microcentrifuge tube. Cell lysate was obtained by centrifugation at top speed for $30 \mathrm{~s}$ in a refrigerated microcentrifuge. The Renilla luciferase activity was determined using the Renilla luciferase assay kit (catalog no. E2810; Promega, Madison, WI, USA), according to the manufacturer's instructions. Luminescence was measured with the microplate reader (Molecular Device, Sunnyvale, CA, USA).

Luciferase assay: Huh7.5/Con1 Cells were plated at $1 \times 10^{5}$ per well in 24-well plates. The next day, the cells were transiently transfected with the empty pGL-3 vector $(4 \mu \mathrm{g})$ or Luc-NF-kB plasmid $(4 \mu \mathrm{g})$ using Lipofectamine ${ }^{\mathrm{TM}} 3000$ reagent for $24 \mathrm{~h}$. All plasmids were kindly gifted by Dr. Joohun Ha (Kyung Hee University, Seoul, Korea). Following transfection, the transfected cells were treated with 2-O-methylhonokiol for 24 or $48 \mathrm{~h}$. The NF-kB-dependent luciferase activity was normalized to the protein concentration measured by Bio-Rad protein assay. Luminescence was measured with the microplate reader (Molecular Device, Sunnyvale, CA, USA). 


\subsection{Quantitative Real-Time Reverse Transcription Polymerase Chain Reaction ( $q$ RT-PCR)}

Total RNA was isolated from Huh7.5 cells expressing the HCV genotype $1 \mathrm{~b}$ subgenomic replicon by using a Trizol reagent (catalog no. 15596026; Invitrogen, Waltham, MA, USA). A cDNA was synthesized from $1.0 \mu \mathrm{g}$ total RNA using RevertAid First Strand cDNA Synthesis Kit (catalog no. K1622; Thermo Fisher Scientific, Waltham, MA, USA). qRT-PCR was performed using 7500 Real-Time PCR system (Applied Biosystems, Foster City, CA, USA) with Power SYBR ${ }^{\circledR}$ Green PCR Master Mix (catalog no. 4309155; Applied Biosystems, Foster City, CA, USA). The integrity of the amplified DNA was confirmed by determining the melting temperature. The relative amounts of mRNA for each gene were optimized by subtracting the $\mathrm{Ct}$ values of each gene' mRNA from the $\mathrm{Ct}$ values of $\beta$-Actin mRNA $(\Delta \mathrm{Ct})$. The $\Delta \mathrm{Ct}$ of the control group was then subtracted from the $\Delta \mathrm{Ct}$ of the 2-O-methyl honokiol-treated groups $(\Delta \Delta \mathrm{Ct})$. Expression levels were normalized to that of $\beta$-actin. Table 1 lists the specific primers for RT-PCR.

Table 1. List of primer couples generated for qRT-PCR.

\begin{tabular}{ccc}
\hline Gene & Direction & Sequence \\
\hline \multirow{2}{*}{ HCV } & $\begin{array}{c}\text { Forward } \\
\text { Reverse }\end{array}$ & GTCTAGCCATGGCGTTAGTATGAG \\
& CTTGTGGTAGCCTGATAGGGT \\
\hline \multirow{2}{*}{ b-Actin } & $\begin{array}{c}\text { Forward } \\
\text { Reverse }\end{array}$ & CATCGAGCACGGCATCGTCA \\
& Forward & TCGAAGTCCAGGGCGACATA \\
\hline \multirow{2}{*}{ TRAF6 } & Reverse & TTTGCTCTTATGGATTGTCCCC \\
& Forward & CATTGATGCAGCACAGTTGTC \\
\hline \multirow{2}{*}{ P65 } & Reverse & CTGTGCGTGTCTCCATGCA \\
& Forward & TCGTCTGTATCTGGCAGGTACTG \\
\hline \multirow{2}{*}{ IFN- $\alpha$} & Reverse & TTTCTCCTGCCTGAAGGACAG \\
& Forward & GCTCATGATTTCTGCTCTGACA \\
\hline \multirow{2}{*}{ MxA } & Reverse & GTTCCTTAGGATTTCCACTCTGACTATGGTCC \\
\hline \multirow{2}{*}{ PKR } & Forward & AACAACCTGTGCAGCCAGTA \\
& Reverse & AAGGGCAACTCCTGAGAGTG \\
\hline & Forward & TCTCTGGCGGTCTTCAGAAT \\
\hline
\end{tabular}

\subsection{Western Blotting}

Cells were lysed in lysis buffer containing $50 \mathrm{mM}$ Tris-Cl, $150 \mathrm{mM} \mathrm{NaCl}, 5 \mathrm{mM}$ EDTA, $0.1 \%$ NP40, and Xpert protease inhibitor cocktail Solution 100 $\times$ (catalog no. p3100-010; GenDEPOT, Barker, TX, USA). Protein concentration was determined by Bradford assay. A $10-12 \%$ SDS-polyacrylamide gel was run under standard electrophoresis conditions, with $30 \mu \mathrm{g}$ of total protein loaded in each lane. Separated proteins were transferred to Immobilon-P membranes (Millipore, Bedford, MA, USA) at $100 \mathrm{~V}$ for $100 \mathrm{~min}$, and incubated with primary antibodies in blocking solution (3\% BSA). Proteins were visualized using the Western blotting luminol reagent (catalog no. sc-2048; Santa Cruz, Dallas, TX, USA). The following antibodies were used: mouse anti-NS5B; 5B-3B1 (Enzo Life Science; Switzerland), mouse anti-NS3; sc-69938, mouse anti-NS4B; sc-52416, mouse anti-NS5A; sc-65458, goat anti-Lamin B; sc-6216, mouse anti- $\alpha$-Actinin; sc- 17829 , mouse anti- $\beta$-actin; sc-47778, mouse anti-TRAF6; sc-8409 (Santa-Cruz, Dallas, TX, USA), rabbit anti-NF-kB(P65); 8242s, rabbit anti-p62; 8025s, and rabbit anti-LC3B; 2775s (Cell signalling, Danvers, MA, USA). All first antibody dilution was 1:1,000. Secondary antibodies used goat anti-mouse IgG; M32607, goat anti-rabbit IgG; 31460 (Invitrogen, Waltham, MA, USA), rabbit antigoat IgG; SA007-500 (GenDEPOT, Barker, TX, USA). All secondary antibody dilution was $1: 10,000$. 


\subsection{Immunoprecipitation}

Treated or non-treated cells were lysed in lysis buffer containing $50 \mathrm{mM}$ Tris-Cl, $150 \mathrm{mM} \mathrm{NaCl}, 12 \mathrm{mM}$ sodium deoxycholate, $1 \%$ Triton $\mathrm{x}-100,0.1 \%$ SDS and Xpert protease inhibitor cocktail Solution 100× (catalog no. p3100-010; GenDEPOT, Barker, TX, USA), and cell lysates were cleared by centrifugation at $14,000 \mathrm{rpm}$ for $15 \mathrm{~min}$ at $4{ }^{\circ} \mathrm{C}$. The lysates $(1 \mathrm{mg})$ were incubated with anti-TRAF6 ( $4 \mathrm{ug})$ for $24 \mathrm{~h}$ at $4{ }^{\circ} \mathrm{C}$. Protein-A/G-conjugated agarose beads were added, followed by incubation for $4 \mathrm{~h}$ at $4{ }^{\circ} \mathrm{C}$. Beads were washed three times with 1X TBST. Immunopellets were boiled with SDS-PAGE sample buffer and resolved by electrophoresis. The following antibodies were used: mouse anti-TRAF6; sc-8409, mouse anti- $\beta$-actin; sc-47778 (Santa-Cruz, Dallas, TX, USA), and rabbit anti-p62; 8025s (Cell signalling, Danvers, MA, USA).

\subsection{Nuclear-Cytosol Fraction}

Cell were grown on $100 \mathrm{~mm}$ tissue culture dishes and harvested with trypsin-EDTA. After mild centrifugation (1000 rpm for $5 \mathrm{~min}$ ), pellets were then fractionated using the NE-PER Nuclear and Cytoplasmic Extraction kit (catalog no. 78833; Thermo Fisher Pierce, Rockfield, IL, USA), according to the manufacturer's instructions. Briefly, harvested cells were washed with $1 \mathrm{~mL}$ ice-cold PBS, and transferred to a $1.5 \mathrm{~mL}$ microcentrifuge tube. Cell pellets were obtained by centrifugation at $500 \times g$ for $3 \mathrm{~min}$ at $4{ }^{\circ} \mathrm{C}$. The supernatant was removed, and the pellet was resuspended in $0.2 \mathrm{~mL}$ ice-cold CER I solution containing protease inhibitors. The suspension was vortexed for $15 \mathrm{~s}$, and placed on ice for $15 \mathrm{~min}$. After the addition of $11 \mu \mathrm{L}$ of CER II solution, the suspension was vortexed for $10 \mathrm{~s}$, placed on ice for $3 \mathrm{~min}$, and vortexed again. The extract was centrifuged at 14,000 rpm for $5 \mathrm{~min}$ at $4{ }^{\circ} \mathrm{C}$, and the supernatant, which represents the cytoplasmic fraction, was removed. The pellet, which contains the nuclei, was washed once with PBS as before, and then resuspended in $50 \mu \mathrm{L}$ of ice-cold NER solution. The nuclei were vortexed for $15 \mathrm{~s}$, and placed on ice for $10 \mathrm{~min}$. This was repeated 3 times for a total of $40 \mathrm{~min}$. The extract was centrifuged as before for $10 \mathrm{~min}$, and the supernatant, which represents the nuclear fraction, was removed. Nuclear and cytoplasmic fractions were prepared in SDS-PAGE sample buffer and were analyzed by SDS-PAGE.

\subsection{Confocal Immunofluorescence Microscopy}

The cells were fixed with $4 \%$ formaldehyde in phosphate-buffered saline (PBS) for $15 \mathrm{~min}$, permeabilized with $0.1 \%$ Triton $\mathrm{x}-100$ in PBS for $15 \mathrm{~min}$, and blocked with $0.1 \%$ NP-40 containing 3\% bovine serum albumin (BSA) for $30 \mathrm{~min}$. Immunofluorescence assays were performed using the rabbit anti-NF-kB(p65) (catalog no. 8242s; cell signalling, Danvers, MA, USA) primary antibodies in 0.1\% NP-40 containing 3\% BSA, dilution 1:100 for $1 \mathrm{~h}$, followed by incubation with goat anti-rabbit Alexa Fluor 594-conjugated secondary antibodies from ThermoFisher Scientific (catalog no. A-11012; Thermo Fisher Scientific, Waltham, MA, USA), dilution 1:100 for $1 \mathrm{~h}$. Then cells were DAPI (Sigma-Aldrich, St. Louis, MO, USA) stained ( $1 \mathrm{mg} / \mathrm{mL}$ ) for $3 \mathrm{~min}$. All images were taken with a Carl Zeiss LSM800 confocal microscopy system. All images were analyzed with Zen Black Edition lite, version 2009.

\subsection{IFN- $\alpha$ ELISA}

After transfection with or without siRNA for $48 \mathrm{~h}$, cells were treated with or without $50 \mu \mathrm{M}$ 2-O-methylhonokiol for 24 or $48 \mathrm{~h}$, and then washed with 1X PBS buffer. Serum-free media was added, and cells were incubated for $24 \mathrm{~h}$. This supernatant was harvested for IFN- $\alpha$ detection using an ELISA kit. The ELISA was performed using the Human IFN- $\alpha$ ELISA kit (Catalog no. E-EL-H6125; Elabscience, Houston, TX, USA), according to the manufacturer's instructions. 


\subsection{Statistical Analysis}

Each experiment was performed at least five times, and the results were expressed as means \pm SD. Depending on the design of the experiment, data were analyzed with Student's $t$-tests and one-way ANOVA/post hoc multicomparison analysis (Tukey's test). A value of $p<0.05$ was considered to be a statistically significant difference. All statistical analysis was performed using Microsoft Excel and VassarStats site (http:/ / vassarstats.net/, access on 18 March 2021).

Supplementary Materials: The following are available online at https:/ /www.mdpi.com/article/ $10.3390 /$ ijms $22126499 / \mathrm{s} 1$.

Author Contributions: Conceptualization, S.J. and W.C.; investigation, S.J., Y.-s.L., K.K. and J.-s.Y.; writing —original draft preparation, S.J.; Project administration, W.C.; writing—review and editing, S.K., J.H., I.K. and W.C. All authors have read and agreed to the published version of the manuscript.

Funding: This research was funded by National Research Foundation of Korea (NRF) grants funded by Korean government (MEST) (grant number NRF-2017R1A2B2002289 and 2018R1A6A1A030525124).

Institutional Review Board Statement: Not applicable.

Informed Consent Statement: Not applicable.

Data Availability Statement: The data that support the findings of this study are available on request from the corresponding author.

Acknowledgments: The antioxidant compounds including 2-O-methylhonokiol were kindly gifted by Jongho Park, Han-bat University, Korea.

Conflicts of Interest: The authors declare no conflict of interest.

$\begin{array}{ll}\text { Abbreviations } \\ \text { HCV } & \text { Hepatitis C virus } \\ \text { NF-kB } & \text { Nuclear factor kappa-light-chain-enhancer of activated B cells } \\ \text { TRAF6 } & \text { Tumor necrosis factor receptor (TNFR)-associated factor 6 } \\ \text { INF } & \text { Interferon } \\ \text { DAA } & \text { Direct Acting Antiviral } \\ \text { PRRs } & \text { Pattern Recognition Receptors } \\ \text { RLRs } & \text { Retinoic acid-inducible gene I product (RIG-I)-like receptors } \\ \text { TLRs } & \text { Toll-like receptors } \\ \text { PAMPs } & \text { Pathogen-associated molecular patterns } \\ \text { LUBAC } & \text { Linear ubiquitin chain assembly complex } \\ \text { PKR } & \text { Protein kinase R } \\ \text { MxA } & \text { Myxovirus resistance protein 1 } \\ \text { CQ } & \text { Chloroquine }\end{array}$

\section{References}

1. Alter, H.J.; Seeff, L.B. Recovery, persistence, and sequelae in hepatitis C virus infection: A perspective on long-term outcome. Semin. Liver Dis. 2000, 20, 17-35. [CrossRef]

2. Fernandez-Caso, B.; Fernandez-Caballero, J.A.; Chueca, N.; Rojo, E.; de Salazar, A.; Garcia Buey, L.; Cardenoso, L.; Garcia, F. Infection with multiple hepatitis $C$ virus genotypes detected using commercial tests should be confirmed using next generation sequencing. Sci. Rep. 2019, 9, 9264. [CrossRef]

3. Polaris Observatory, H.C.V.C. Global prevalence and genotype distribution of hepatitis C virus infection in 2015: A modelling study. Lancet Gastroenterol. Hepatol. 2017, 2, 161-176. [CrossRef]

4. Messina, J.P.; Humphreys, I.; Flaxman, A.; Brown, A.; Cooke, G.S.; Pybus, O.G.; Barnes, E. Global distribution and prevalence of hepatitis $C$ virus genotypes. Hepatology 2015, 61, 77-87. [CrossRef] [PubMed]

5. Nguyen, P.; Vutien, P.; Hoang, J.; Trinh, S.; Le, A.; Yasukawa, L.A.; Weber, S.; Henry, L.; Nguyen, M.H. Barriers to care for chronic hepatitis C in the direct-acting antiviral era: A single-centre experience. BMJ Open Gastroenterol. 2017, 4, e000181. [CrossRef]

6. Sandmann, L.; Schulte, B.; Manns, M.P.; Maasoumy, B. Treatment of Chronic Hepatitis C: Efficacy, Side Effects and Complications. Visc. Med. 2019, 35, 161-170. [CrossRef] 
7. Puoti, M.; Foster, G.R.; Wang, S.; Mutimer, D.; Gane, E.; Moreno, C.; Chang, T.T.; Lee, S.S.; Marinho, R.; Dufour, J.F.; et al. High SVR12 with 8-week and 12-week glecaprevir/pibrentasvir therapy: An integrated analysis of HCV genotype 1-6 patients without cirrhosis. J. Hepatol. 2018, 69, 293-300. [CrossRef] [PubMed]

8. Vermehren, J.; Park, J.S.; Jacobson, I.M.; Zeuzem, S. Challenges and perspectives of direct antivirals for the treatment of hepatitis C virus infection. J. Hepatol. 2018, 69, 1178-1187. [CrossRef]

9. Bastos, J.C.; Padilla, M.A.; Caserta, L.C.; Miotto, N.; Vigani, A.G.; Arns, C.W. Hepatitis C virus: Promising discoveries and new treatments. World J. Gastroenterol. 2016, 22, 6393-6401. [CrossRef]

10. Liu, S.; Li, L.; Tan, L.; Liang, X. Inhibition of Herpes Simplex Virus-1 Replication by Natural Compound Honokiol. Virol. Sin. 2019, 34, 315-323. [CrossRef]

11. Sam, S. Importance and effectiveness of herbal medicines. J. Pharmacogn. Phytochem. 2019, 8, 354-357.

12. Lan, K.H.; Wang, Y.W.; Lee, W.P.; Lan, K.L.; Tseng, S.H.; Hung, L.R.; Yen, S.H.; Lin, H.C.; Lee, S.D. Multiple effects of Honokiol on the life cycle of hepatitis C virus. Liver Int. 2012, 32, 989-997. [CrossRef]

13. Chaplin, D.D. Overview of the immune response. J. Allergy Clin. Immunol. 2010, 125, S3-S23. [CrossRef]

14. Lee, J.; Tian, Y.; Chan, S.T.; Kim, J.Y.; Cho, C.; Ou, J.H. TNF- $\alpha$ Induced by Hepatitis C Virus via TLR7 and TLR8 in Hepatocytes Supports Interferon Signaling via an Autocrine Mechanism. PLoS Pathog. 2015, 11, e1004937. [CrossRef] [PubMed]

15. Takeuchi, O.; Akira, S. Innate immunity to virus infection. Immunol. Rev. 2009, 227, 75-86. [CrossRef]

16. Horner, S.M.; Gale, M., Jr. Regulation of hepatic innate immunity by hepatitis C virus. Nat. Med. 2013, 19, 879-888. [CrossRef]

17. Chan, S.T.; Lee, J.; Narula, M.; Ou, J.J. Suppression of Host Innate Immune Response by Hepatitis C Virus via Induction of Autophagic Degradation of TRAF6. J. Virol. 2016, 90, 10928-10935. [CrossRef]

18. Hayden, M.S.; Ghosh, S. NF-kB in immunobiology. Cell Res. 2011, 21, 223-244. [CrossRef]

19. Park, J.; Kang, W.; Ryu, S.W.; Kim, W.I.; Chang, D.Y.; Lee, D.H.; Park, D.Y.; Choi, Y.H.; Choi, K.; Shin, E.C.; et al. Hepatitis C virus infection enhances TNF $\alpha$-induced cell death via suppression of NF-KB. Hepatology 2012, 56, 831-840. [CrossRef]

20. Chen, Y.; He, L.; Peng, Y.; Shi, X.; Chen, J.; Zhong, J.; Chen, X.; Cheng, G.; Deng, H. The hepatitis C virus protein NS3 suppresses TNF- $\alpha$-stimulated activation of NF-kB by targeting LUBAC. Sci. Signal. 2015, 8, ra118. [CrossRef]

21. Dreux, M.; Gastaminza, P.; Wieland, S.F.; Chisari, F.V. The autophagy machinery is required to initiate hepatitis $C$ virus replication. Proc. Natl. Acad. Sci. USA 2009, 106, 14046-14051. [CrossRef]

22. Taguwa, S.; Kambara, H.; Fujita, N.; Noda, T.; Yoshimori, T.; Koike, K.; Moriishi, K.; Matsuura, Y. Dysfunction of autophagy participates in vacuole formation and cell death in cells replicating hepatitis C virus. J. Virol. 2011, 85, 13185-13194. [CrossRef]

23. Shrivastava, S.; Bhanja Chowdhury, J.; Steele, R.; Ray, R.; Ray, R.B. Hepatitis C virus upregulates Beclin1 for induction of autophagy and activates mTOR signaling. J. Virol. 2012, 86, 8705-8712. [CrossRef] [PubMed]

24. Bjorkoy, G.; Lamark, T.; Brech, A.; Outzen, H.; Perander, M.; Overvatn, A.; Stenmark, H.; Johansen, T. p62/SQSTM1 forms protein aggregates degraded by autophagy and has a protective effect on huntingtin-induced cell death. J. Cell Biol. 2005, 171, 603-614. [CrossRef]

25. Kabeya, Y.; Mizushima, N.; Ueno, T.; Yamamoto, A.; Kirisako, T.; Noda, T.; Kominami, E.; Ohsumi, Y.; Yoshimori, T. LC3, a mammalian homologue of yeast Apg8p, is localized in autophagosome membranes after processing. EMBO J. 2000, 19, 5720-5728. [CrossRef]

26. Mizui, T.; Yamashina, S.; Tanida, I.; Takei, Y.; Ueno, T.; Sakamoto, N.; Ikejima, K.; Kitamura, T.; Enomoto, N.; Sakai, T.; et al. Inhibition of hepatitis C virus replication by chloroquine targeting virus-associated autophagy. J. Gastroenterol. 2010, 45, 195-203. [CrossRef]

27. Luo, S.; Wang, Y.; Zhao, M.; Lu, Q. The important roles of type I interferon and interferon-inducible genes in systemic lupus erythematosus. Int. Immunopharmacol. 2016, 40, 542-549. [CrossRef]

28. Bave, U.; Nordmark, G.; Lovgren, T.; Ronnelid, J.; Cajander, S.; Eloranta, M.L.; Alm, G.V.; Ronnblom, L. Activation of the type I interferon system in primary Sjogren's syndrome: A possible etiopathogenic mechanism. Arthritis Rheum. 2005, 52, 1185-1195. [CrossRef]

29. Kim, K.; Lee, Y.S.; Jeong, S.; Kim, D.; Chon, S.; Pak, Y.K.; Kim, S.; Ha, J.; Kang, I.; Choe, W. A Small Molecule, 4-Phenylbutyric Acid, Suppresses HCV Replication via Epigenetically Induced Hepatic Hepcidin. Int. J. Mol. Sci. 2020, 21, 5516. [CrossRef]

30. Meng, X.; Yang, D.; Yu, R.; Zhu, H. EPSTI1 Is Involved in IL-28A-Mediated Inhibition of HCV Infection. Mediators Inflamm. 2015, 2015, 716315. [CrossRef]

31. Shi, X.; Jiao, B.; Chen, Y.; Li, S.; Chen, L. MxA is a positive regulator of type I IFN signaling in HCV infection. J. Med. Virol. 2017, 89, 2173-2180. [CrossRef]

32. Giannelli, G.; Guadagnino, G.; Dentico, P.; Antonelli, G.; Antonaci, S. MxA and PKR expression in chronic hepatitis C. J. Interferon Cytokine Res. 2004, 24, 659-663. [CrossRef]

33. Carmona, F.; Pereira, A.M.S. Herbal medicines: Old and new concepts, truths and misunderstandings. Rev. Bras. Farmacogn. 2013, 23, 379-385. [CrossRef]

34. Dar, R.A.; Shahnawaz, M.; Qazi, P.H. General overview of medicinal plants: A review. J. Phytopharmacol. 2017, 6, 349-351.

35. Abdel-Aziz, S.M.; Aeron, A.; Kahil, T.A. Health benefits and possible risks of herbal medicine. In Microbes in Food and Health; Springer: Berlin/Heidelberg, Germany, 2016; pp. 97-116. 
36. Randall, G.; Panis, M.; Cooper, J.D.; Tellinghuisen, T.L.; Sukhodolets, K.E.; Pfeffer, S.; Landthaler, M.; Landgraf, P.; Kan, S.; Lindenbach, B.D.; et al. Cellular cofactors affecting hepatitis $C$ virus infection and replication. Proc. Natl. Acad. Sci. USA 2007, 104, 12884-12889. [CrossRef]

37. Tian, H.; He, Z. miR-215 Enhances HCV Replication by Targeting TRIM22 and Inactivating NF-кB Signaling. Yonsei Med. J. 2018, 59, 511-518. [CrossRef] [PubMed]

38. Zhang, L.; Alter, H.J.; Wang, H.; Jia, S.; Wang, E.; Marincola, F.M.; Shih, J.W.; Wang, R.Y. The modulation of hepatitis C virus 1a replication by PKR is dependent on NF-kB mediated interferon beta response in Huh7.5.1 cells. Virology 2013, 438, 28-36. [CrossRef]

39. Ahn, K.S.; Sethi, G.; Shishodia, S.; Sung, B.; Arbiser, J.L.; Aggarwal, B.B. Honokiol potentiates apoptosis, suppresses osteoclastogenesis, and inhibits invasion through modulation of nuclear factor-kappaB activation pathway. Mol. Cancer Res. 2006, 4, 621-633. [CrossRef]

40. Fang, C.Y.; Chen, S.J.; Wu, H.N.; Ping, Y.H.; Lin, C.Y.; Shiuan, D.; Chen, C.L.; Lee, Y.R.; Huang, K.J. Honokiol, a Lignan Biphenol Derived from the Magnolia Tree, Inhibits Dengue Virus Type 2 Infection. Viruses 2015, 7, 4894-4910. [CrossRef]

41. Chen, X.; Hu, Y.; Shan, L.; Yu, X.; Hao, K.; Wang, G.X. Magnolol and honokiol from Magnolia officinalis enhanced antiviral immune responses against grass carp reovirus in Ctenopharyngodon idella kidney cells. Fish Shellfish. Immunol. 2017, 63, 245-254. [CrossRef]

42. Wu, H.; Arron, J.R. TRAF6, a molecular bridge spanning adaptive immunity, innate immunity and osteoimmunology. Bioessays 2003, 25, 1096-1105. [CrossRef]

43. Sun, L.; Deng, L.; Ea, C.K.; Xia, Z.P.; Chen, Z.J. The TRAF6 ubiquitin ligase and TAK1 kinase mediate IKK activation by BCL10 and MALT1 in T lymphocytes. Mol. Cell 2004, 14, 289-301. [CrossRef]

44. Deng, L.; Wang, C.; Spencer, E.; Yang, L.; Braun, A.; You, J.; Slaughter, C.; Pickart, C.; Chen, Z.J. Activation of the IkappaB kinase complex by TRAF6 requires a dimeric ubiquitin-conjugating enzyme complex and a unique polyubiquitin chain. Cell 2000, 103, 351-361. [CrossRef]

45. Darnay, B.G.; Ni, J.; Moore, P.A.; Aggarwal, B.B. Activation of NF-kB by RANK requires tumor necrosis factor receptor-associated factor (TRAF) 6 and NF-кB-inducing kinase. Identification of a novel TRAF6 interaction motif. J. Biol. Chem. 1999, 274, 7724-7731. [CrossRef] [PubMed]

46. Knodler, L.A.; Celli, J. Eating the strangers within: Host control of intracellular bacteria via xenophagy. Cell. Microbiol. 2011, 13, 1319-1327. [CrossRef]

47. Choi, Y.; Bowman, J.W.; Jung, J.U. Autophagy during viral infection-A double-edged sword. Nat. Rev. Microbiol. 2018, 16, 341-354. [CrossRef] [PubMed]

48. Wang, L.; Ou, J.H. Hepatitis C virus and autophagy. Biol. Chem. 2015, 396, 1215-1222. [CrossRef] 